\title{
ENETS Consensus Guidelines for the Standards of Care in Neuroendocrine Tumors: Pre- and Perioperative Therapy in Patients with Neuroendocrine Tumors
}

\author{
Gregory Kaltsas $^{a} \quad$ Martyn Caplin $^{b}$ Philippa Davies ${ }^{b}$ Diego Ferone ${ }^{c}$ \\ Rocio Garcia-Carbonero ${ }^{d}$ Simona Grozinsky-Glasberg ${ }^{\text {e Dieter Hörsch }}{ }^{f}$ \\ Eva Tiensuu Janson ${ }^{g}$ Reza Kianmanesh ${ }^{\mathrm{h}}$ Beata Kos-Kudla ${ }^{\mathrm{i}}$ Marianne Pavel ${ }^{j}$ \\ Anja Rinkek $^{k}$ Massimo Falconi ${ }^{l}$ Wouter W. de Herder ${ }^{m}$ all other Antibes \\ Consensus Conference participants \\ a Endocrine Unit, Department of Pathophysiology, National and Kapodistrian University of Athens, Athens, Greece; \\ ${ }^{b}$ Neuroendocrine Tumour Unit, Royal Free Hospital, London, UK; ' Endocrinology Unit, Department of Internal \\ Medicine and Medical Specialties (DiMI), Center of Excellence for Biomedical Research (CEBR), IRCCS AOU San \\ Martino-IST, University of Genova, Genova, Italy; ${ }^{\mathrm{d}}$ Medical Oncology Department, Hospital Universitario Doce \\ de Octubre, Madrid, Spain; ${ }^{e}$ Neuroendocrine Unit, Endocrinology and Metabolism Service, Hadassah-Hebrew \\ University Medical Center, Jerusalem, Israel; ${ }^{\mathfrak{f} G a s t r o e n t e r o l o g y ~ a n d ~ E n d o c r i n o l o g y ~ C e n t e r ~ f o r ~ N e u r o e n d o c r i n e ~}$ \\ Tumors Bad Berka, Bad Berka, Germany; ${ }^{9}$ Department of Endocrine Oncology, Uppsala University Hospital, Uppsala,

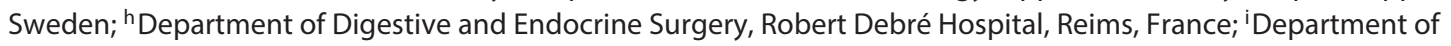 \\ Pathophysiology and Endocrinology, Division of Endocrinology, Medical University of Silesia, Katowice, Poland; \\ jDepartment of Hepatology and Gastroenterology, Campus Virchow Klinikum, Charité Universitätsmedizin Berlin, \\ Berlin, and ${ }^{k}$ Department of Gastroenterology, UKGM Marburg and Philipps University Marburg, Marburg, Germany; \\ 'Chirurgia del Pancreas, Pancreas Translational and Clinical Research Center, Ospedale San Raffaele, Università "Vita \\ e Salute", Milano, Italy; 'mENETS Centre of Excellence, Erasmus MC Cancer Centre, Rotterdam, The Netherlands
}

\section{Keywords}

Neuroendocrine tumor · Carcinoid · Carcinoid syndrome ·

Carcinoid heart disease

\section{Abstract}

Neuroendocrine tumors of the small intestine are the most common causes of the carcinoid syndrome. Carcinoid heart disease occurs in more than half of the patients with the carcinoid syndrome. Patients with carcinoid heart disease who

\section{KARGER}

E-Mail karger@karger.com www.karger.com/nen
This article is licensed under the Creative Commons AttributionNonCommercial-NoDerivatives 4.0 International License (CC BYNC-ND) (http://www.karger.com/Services/OpenAccessLicense) tribution of modified material requires written permission. need to undergo surgery should also undergo preoperative evaluation by an expert cardiologist. Treatment with longacting somatostatin analogs aims at controlling the excessive hormonal output and symptoms related to the carcinoid syndrome and at preventing a carcinoid crisis during interventions. Patients with a gastrinoma require pre- and postoperative treatment with high doses of proton pump inhibitors. Patients with a glucagonoma require somatostatin analog treatment and nutritional supplementation. $\mathrm{Pa}$ tients with a VIPoma also require somatostatin analog treat- 
ment and intravenous fluid and electrolyte therapy. Insulinoma patients generally require intravenous glucose infusion prior to operation. In patients with localized operable insulinoma, somatostatin analog infusion should only be considered after the effect of this therapy has been electively studied.

(c) 2017 The Author(s)

Published by S. Karger AG, Basel

\section{Introduction}

\section{Preoperative Diagnostic Procedures}

Prior to surgery or other interventional treatment in patients with neuroendocrine tumors (NET), the tumor type and hormone production must be assessed in order to provide appropriate treatments as well as to avoid lifethreatening crises that may occur due to the presence of hormonal syndromes associated with some of these tumors [1]. In addition, the presence of any triggering factors should be determined.

A low threshold for further cardiac workup should be utilized in patients with the carcinoid syndrome, employing NT-proBNP measurements and echocardiography, or cardiac magnetic resonance imaging, since the reported incidence of different grades of cardiac involvement could be as high as 50\% [2]. However, more recent studies suggest that the prevalence of carcinoid heart disease (CHD) has decreased during the last decades to about $20 \%$, probably due to the use of somatostatin analogs [3].

\section{Carcinoid Syndrome: Pre- and Perioperative Therapy}

\section{Carcinoid Syndrome}

NET of the small intestine are the most common causes of the carcinoid syndrome that occurs in $20-30 \%$ of patients with liver metastases from these NET. The classical (typical) carcinoid syndrome is usually characterized by cutaneous flushing, gut hypermobility with diarrhea and bronchospasm with wheezing and shortness of breath [4]. The syndrome is occasionally also encountered in patients with large lymph nodes, peritoneal, ovarian lesions (primary or metastases) or bronchial carcinoids, where secretory products exceed the capacity of inactivation by the liver, or bypass the liver being released directly into the systemic circulation $[5,6]$. Preoperatively, patients with small intestinal NET need to be carefully evaluated and treated for manifestations of the carcinoid tumor, paying particular attention to reveal previously unnoticed diarrhea or flushing, and incipient CHD, and in such cases protective actions should be taken to prevent a carcinoid crisis during surgery $[7,8]$. Patients with or without carcinoid syndrome may present with large desmoplastic fibrotic reactions of the peritoneum usually around the involved lymph nodes, which may cause obstructive associated symptoms.

\section{Preoperative Fluid Electrolyte, Vitamin, and Protein Abnormalities}

Diarrhea in patients with carcinoid syndrome may cause dehydration, electrolyte abnormalities, and hypoproteinemia $[7,8]$. In the presence of carcinoid syndrome, the essential amino acid tryptophan is converted to serotonin, leaving inadequate amounts of tryptophan for conversion to niacin and proteins, which contributes to hypoproteinemia [8]. Niacin deficiency may cause pellagra, with dermatitis, diarrhea, and dementia [9]. In addition, deficiencies of other fat-soluble vitamins, following prior treatment with somatostatin analogs, should be looked for and adequately substituted [10]. Patients with severe diarrhea, weight loss and hypoproteinemia require parenteral nutrition with adequate supplementation before surgery is undertaken.

\section{Carcinoid Heart Disease}

$\mathrm{CHD}$ occurs in more than half of the patients with carcinoid syndrome, with serotonin being an important mediator [11-13]. However, it can remain undiagnosed as shown in a recent study of 150 patients with carcinoid syndrome, of whom $37 \%$ with CHD exhibited no physical signs [14].

Fibrotic plaques affect the valves and cavities of the right ventricle, with thickening of valvular leaflets and shortening of the chordae tendineae, resulting in tricuspid regurgitation and pulmonary stenosis. Tricuspid valves have been affected in $95 \%$ of patients, while pulmonary valves have been less frequently involved. Left-sided valvular lesions are rare because mediators are cleared or inactivated in the lungs before reaching the left side of the heart, but can occur due to patent foramen ovale, lung tumors or overwhelming disease. Concomitant mitral and aortic regurgitation has occasionally been demonstrated $[12,13]$. A 5-hydroxyindoleacetic acid (5-HIAA) level of $\geq 300 \mu \mathrm{mol} / 24 \mathrm{~h}$ and $\geq 3$ episodes of flushing per day are considered to be independent predictors of the development or progression of CHD [3]. It has recently been suggested that plasma 5-HIAA measurements could also serve as an additional tumor marker that could potentially ameliorate the need of urinary 5-HIAA measurements [15]. 
Diagnosis of CHD is difficult, and cardiac symptoms do not appear until late stages of the disease. Diagnosis of CHD requires 2-dimensional echocardiography and Doppler examination to assess the severity of valvular stenosis and regurgitation (CHD guidelines) [13]. Moreover, NT-proBNP has been shown to exert a high sensitivity and specificity ( 87 and $80 \%$, respectively) in predicting CHD and it has also been shown to correlate with patient survival [16]. Severe tricuspid regurgitation also strongly correlates with poor survival in patients with carcinoid syndrome.

In patients with carcinoid valvular heart disease, morbidity from abdominal operation is markedly increased. CHD poses 2 distinct challenges for the anesthesiologist: carcinoid crisis and low cardiac output syndrome secondary to right ventricular failure [17]. Patients may have incipient cardiac failure and be poor candidates for surgery, or they may fail to recover after operation. Moreover, right-sided heart failure increases central venous pressure and may markedly increase the risk of bleeding, from hepatic veins, especially during liver surgery [13]. Echocardiography should be done in all patients with the carcinoid syndrome, and patients with moderate CHD should always be discussed with cardiologists before surgery. In case of significant heart disease, a cardiothoracic surgical evaluation and possible surgical valvular replacement may be required before major abdominal operation $[13,17,18]$.

Reconstructive valve replacement surgery has been reported to be of obvious value for patients with advanced heart disease and right ventricular failure, with low mortality in young patients but high risk in patients older than 60 years of age $[11,19,20]$. However, in a recent metaanalysis, age was not found to be a contributing factor of higher mortality [21]. During cardiac surgery, risks for carcinoid crisis may be high because patients often require vasoactive medication to support the circulatory system, which may trigger carcinoid crisis [2]. In a series of 22 patients who underwent valve replacement, 4 died within 30 days postoperatively and in 1 of them carcinoid crisis was the main cause of death [3]. There is still controversy regarding the use of vasoconstrictor amines in case of hypotension as there are several reports in favor of and against their use $[7,8,19]$. However, approximately $90 \%$ of 11 patients who underwent valvular replacement and received inotropic agents to wean them off, cardiopulmonary bypass did not experience any symptomatic exacerbation while being on concomitant octreotide cover [17]. In addition, patients pretreated with long-acting somatostatin analogs required higher doses of octreotide infusions (median 320 vs. $750 \mu \mathrm{g}$ ) [17].

Pre- and Perioperative Therapy in

Patients with Neuroendocrine Tumours

\section{Carcinoid Crisis}

Patients with carcinoid syndrome are at risk for developing a carcinoid crisis during either minor or major surgery or other types of intervention, such as arterial embolization, radiofrequency ablation, endoscopic procedures, diagnostic procedures or treatment with peptide receptor radionuclide therapy $[7,8,22-25]$. The presence of CHD and high 5-HIAA levels have been shown to represent predictors of an emerging carcinoid crisis [26]. Patients undergoing such procedures or minor operations should be carefully assessed for the presence of such risks and relevant therapeutic interventions should be utilized if required. The crisis may also be provoked by severe emotional stress, induction of anesthesia during ravage of the abdomen, or as a result of tumor manipulation or tumor necrosis during surgery or intervention [27].

Patients with carcinoid crisis may have sudden changes in blood pressure, most often hypotension, sometimes combined with prolonged and excessive flushing, hyperthermia, and occasional bronchospasm. Some may have attacks of hypertension and occasional hypertensive crisis due to tumor release of catecholamines [28-30]. Patients with large tumor load, high chromogranin A levels, or high urinary 5-HIAA values are more likely to experience a carcinoid crisis during surgery; however, not all of these risk factors have consistently been confirmed [2]. Catecholamines released from the adrenals or sympathetic neurons are thought to contribute to the release of tumor products, and thus appropriate pain relief can reduce the stress response $[7,8,27]$. This is particularly important as intraoperative hypotension may occur in both functioning and apparently nonfunctioning tumors with the most important predictor being the presence of hepatic metastases [27].

Sometimes the crisis complication presents with vague symptoms, and patients continue to be unstable postoperatively, or fail to recover after surgery, which emphasizes the importance of being aware of an undiagnosed carcinoid crisis, possibly reversible with appropriate treatment [31]. Previous treatment with long-acting somatostatin analogs aims at controlling the excessive hormonal output and symptoms related to the carcinoid syndrome and prevent a carcinoid crisis. In some cases, addition of ondansetron may help control the diarrhea [32].

The ideal scheme and dosing of octreotide to prevent the development of a carcinoid crisis have not been clearly established [27, 31]. Acute intravenous administration of octreotide has been reported to provide rapid reversal of a carcinoid crisis, and the current focus of carcinoid

Neuroendocrinology 2017;105:245-254 DOI: $10.1159 / 000461583$ 
therapy is to prevent mediator release with octreotide prophylaxis $[2,7,8,18,22,26,31]$. This has largely replaced the use of other drugs for acute treatment. If patients already receive long-acting somatostatin analogs, these medications should continue. However, as intraoperative carcinoid events are not easily predicted, there is no standard octreotide administration regimen and various schemes have been proposed [2]. It has been suggested that for minor procedures or lower-risk patients, a reasonable scheme is the subcutaneous administration of octreotide 100-200 $\mu \mathrm{g}$ 2-3 times/day during surgery [2]. However, as a carcinoid crisis can also be induced even with minor surgical procedures, intravenous octreotide infusions should also be readily available to be used when necessary. For elective intra-abdominal or other major operations, the administration of octreotide $100 \mu \mathrm{g} 3$ times/day subcutaneously for 2 weeks has been suggested prior to surgery $[2,33]$. However, intravenous octreotide is currently considered the most preferable mode of administration [31]. With acute operations, octreotide is beneficial even if given for only $24 \mathrm{~h}$ before surgery, since this may achieve adequate suppression of basal amine and peptide levels [34]. However, a single dose of $500 \mu \mathrm{g}$ of octreotide was shown not to be sufficient to inhibit perioperative complications as well as previous treatment with somatostatin analogs [27]. Perioperative prophylactic treatment with intravenous octreotide, at a starting dose of $50-100 \mu \mathrm{g} / \mathrm{h}$ (mean dose $100-200 \mu \mathrm{g} / \mathrm{h}$ ) is currently used by most centers as an appropriate regimen and shown to successfully prevent crisis during major surgery with little side effects in some studies $[7,8]$. Although this has not been substantiated by any prospective study, most experts initiate treatment with intravenous octreotide $12 \mathrm{~h}$ before escalating the dose as necessary until symptom control and continued at least $48 \mathrm{~h}$ after the operation with dose titration as required. Some patients may still have symptoms and require additional intravenous octreotide and doses up to $500 \mu \mathrm{g} / \mathrm{h}$ have been administered $[2,31]$. A study that formally assessed the efficacy of octreotide in preventing carcinoid crisis has found that intraoperative complications (e.g., flushing, sustained hypotension, bronchospasm, acidosis $[\mathrm{pH}$ $<7.2$ ], and ventricular tachycardia) developed in $11 \%$ of patients who did not receive the medication compared to none of those who received intraoperative octreotide $(p=$ $0.023)$. In addition, a recent meta-analysis has suggested that patients pretreated with somatostatin analogs (mainly octreotide) may require even higher doses [31]. However, although octreotide is of proven value in preventing and treating carcinoid crisis, the current literature relies on small sample size studies and relatively low quality of data. In addition, the inconsistent use of the term carcinoid crisis and the paucity of reported articles preclude the adaption of a universally accepted octreotide dosing scheme $[2,31]$.

\section{Atypical Carcinoid Syndrome}

A less common atypical carcinoid syndrome may be encountered in patients with tumors originating from the foregut including mostly the lung, but also the stomach and duodenum $[6,35]$. The syndrome consists of patchy, intensely red flush, sweating, itching, sometimes also cutaneous edema, bronchoconstriction, salivary gland swelling, lacrimation, and cardiovascular instability mainly manifested as hypotension $[6,35]$. It is usually encountered in patients with liver metastases and is due to the release of both histamine and serotonin. Patients with the atypical carcinoid syndrome have a decarboxylation deficit and therefore only seldom have excess urinary excretion of the serotonin metabolite 5-HIAA $[6,36]$. Urinary estimates of the histamine metabolite methylimidazole acetic acid may serve as a tumor marker $[22,36]$. Cytoreductive surgery or hepatic artery embolization may occasionally be contraindicated due to the risk of uncontrolled release reactions.

In the presence of an atypical carcinoid syndrome, the patients should be treated with octreotide before and during surgery or intervention $[6,35]$ (see Atypical Carcinoid Syndrome). Patients with the severest reactions (e.g., mainly patients with lung carcinoids) may require higher doses of octreotide $(100-200 \mu \mathrm{g} / \mathrm{h})$ and sometimes also saline infusion $[6,35]$. Histamine-liberating substances like morphine or tubocurarine and adrenergic drugs should be avoided during anesthesia as they may cause further histamine release and lead to the development of hypotension [2]. Combination with $\mathrm{H}_{1}$ receptor blockers (loratadine) and $\mathrm{H}_{2}$ blockers (ranitidine) is recommended in the presence of severe symptoms, and sometimes also cortisone (dexamethasone), since histamine release and its peripheral actions may not be blocked by somatostatin analogs $[6,36]$.

\section{Specific Recommendations Concerning Anesthesia}

Premedication

Premedication is focused on relieving existing symptoms and preparing for a potential carcinoid crisis [37]. All patients' maintenance medications should be continued and benzodiazepines and antihistamines could be used to decrease anxiety and stress [7]. Monitoring the central venous pressure may aid in fluid management, 
but interpretation may be difficult in the presence of CHD with tricuspid regurgitation or pulmonary stenosis $[7,8]$. As rapid blood pressure changes are commonly encountered in such patients, invasive monitoring is typically required; it is started before the induction of anesthesia and maintained throughout the procedure [2]. Arterial catheter monitoring is considered for major surgery since the hypotension seen with induction agents may trigger a carcinoid crisis [38]. Accurate airway pressure monitoring is necessary to rapidly detect the onset of bronchospasm whereas continuous temperature monitoring and warming devices are needed as hypothermia could trigger a carcinoid crisis [2].

Drugs that stimulate the sympathetic nervous symptoms or cause histamine release such as morphine and $d$-tubocurarine should be avoided [33]. Propofol, thiopental sodium, and etomidate have been used to induce anesthesia. Propofol has a more profound effect in suppressing catecholamine release and may be the best agent in patients with carcinoid syndrome as long as hypotension is avoided [39]. Furthermore, only nondepolarizing neuromuscular blockers that do not cause histamine release should be used [7]. Due to its cardiovascular stability, vecuronium and rocuronium can be safely used [2]. Safe use of succinylcholine has also been documented. During maintenance of anesthesia, special attention should be paid to avoid right ventricular overload and strain to prevent right ventricular failure and the development of cardiovascular alterations that mostly present as blood pressure and heart rate instability rather than rhythm abnormalities [2, 7].

Hypotension is the most common problem during anesthesia, but in this situation sympathomimetic drugs should be avoided, since they may worsen hypotension by triggering further release of peptides. However, this view is not widely accepted as several reports have shown that the use of inotropic agents along with octreotide can restore the cardiovascular instability $[2,27]$. Hypotension tends to occur when large bulky metastases are manipulated and in such instances stopping the procedure until hemodynamic control is restored is a simple maneuver $[7,8]$. Intravenous octreotide can correct hypotension within $10 \mathrm{~min}$ and thereafter, and is used in combination with volume expanders.

Hypertension is also treated by prevention of peptide release with octreotide, and by increasing the depth of anesthesia. Bronchospasm can occasionally be severe, and since $\beta$-receptor agonists and theophylline may precipitate mediator release and worsen bronchospasm, they should be used with extreme care $[7,8]$. Octreotide may

Pre- and Perioperative Therapy in

Patients with Neuroendocrine Tumours be used for the release of bronchospasm, and steroids (dexamethasone) may still have a role in such patients. Flushing may occur and may in itself not be problematic but it is a warning of potential cardiovascular instability, and indicates increased requirement of octreotide. Recovery from anesthesia may also be substantially delayed $[27,40]$.

\section{Postoperative Period}

Preoperative treatment with octreotide should continue and should cease slowly over the first postoperative week rather than stop abruptly. Hypovolemia and pain causing sympathetic stimulation should be avoided in the postoperative period. Non-histamine-releasing opioids such as fentanyl have been used with no adverse effects for postoperative analgesia. Endocarditis prophylaxis may be required if significant carcinoid-induced valvular heart disease is present, although this approach is still a matter of debate [41]. Epidural and spinal anesthesia have been successfully used in patients with carcinoid tumors mainly undergoing noncarcinoid surgery [42]. Care should be taken to evaluate and premedicate these patients adequately, as hypotension may commonly occur with these techniques [2].

\section{Pancreaticoduodenal NET: Pre- and Perioperative Therapy}

Among patients with pancreaticoduodenal NET, preoperative and prolonged postoperative treatment with adequately high dosed proton pump inhibitors (PPIs) is needed for patients with gastrinoma mainly to prevent gastrojejunal bleeding, and perioperative glucose monitoring is used to avoid hypoglycemia in patients with insulinoma. Patients with glucagonoma require somatostatin analog treatment and nutritional supplementation to heal the skin lesion prior to surgery, and perioperative anticoagulation to prevent thrombosis. Patients with VIPoma need to be resuscitated with preoperative somatostatin analog treatment and intravenous fluid and electrolyte therapy before being subjected to surgery $[1,6]$.

In some studies, perioperative somatostatin or somatostatin analog treatment has been demonstrated to result in a significant reduction in the pancreatic fistula rate after elective pancreatic surgery, without having an influence on postoperative mortality [43]. Octreotide 100-200 $\mu \mathrm{g}$ subcutaneously 3-4 times/day for 6-8 days may reduce the risk for fistulation and minimize leakage after a difficult resection or enucleation of endocrine pancreatic

Neuroendocrinology 2017;105:245-254 DOI: $10.1159 / 000461583$ 
tumors, but may not be routinely required. However, recent prospective trials showed that such an approach had no effect [44, 45]. If somatostatin has been used, it should be weaned slowly rather than discontinued abruptly. Patients subjected to splenectomy in association with removal of an endocrine pancreatic tumor are given vaccinations against meningococcus and Haemophilus influenza and Pneumovax the day prior to hospital discharge to prevent postsplenectomy sepsis.

\section{Gastrinoma}

Gastrinomas are predisposed to gastrointestinal perforation and hemorrhage, which may cause death after pancreaticoduodenectomy. During and 3 months after surgery, patients need adequately high doses of PPIs to efficiently control the acid hypersecretion that persists even after removal of the primary tumor mainly by residual hypertrophy of gastric mucosa [46]. The dose of antisecretory drug is titrated to reduce the acid hypersecretion to $\leq 10 \mathrm{mEq} / \mathrm{h}$, or to lower values in patients with previous acid-reducing surgery or severe reflux disease. High initial doses of PPIs (such as $60-80 \mathrm{mg}$ /day of omeprazole) are frequently prescribed, with dose adjustment as necessary based on symptom response. In the acute setting where oral medications may be contraindicated, intravenous formulations are effective. A starting dose of $80 \mathrm{mg}$ of pantoprazole given by a 15 -min infusion every $8 \mathrm{~h}$ was recommended because it controlled gastric acid hypersecretion in all Zollinger-Ellison syndrome patients studied both acutely and up to 7 days [47]. However, many specialized pancreatic centers preconize to treat patients with high doses of PPIs following 1-3 months after pancreaticoduodenectomy. Octreotide can be used to treat Zollinger-Ellison syndrome but it does not add significantly to the acid-reducing effect of PPIs, which is the preferred medication [48]. Patients should maintain their medication with PPIs for some weeks after surgery since many continue to hypersecrete acid for some time [49].

\section{Insulinoma}

Preoperative diazoxide treatment is sometimes used to control hypoglycemia prior to operation, but may cause severe fluid retention and edema in some patients. It is generally not recommended prior to surgery for benign insulinoma. Patients with insulinoma and significant hypoglycemia should preferably be submitted to surgery without delay, and without diazoxide. At times of hypoglycemia, dextrose administration, intramuscular glucagon, and potassium replacement may be required as a res- cue procedure. Patients with severe hypoglycemia may require intravenous glucose infusion on the night prior to operation to avoid risk of unrecognized hypoglycemia [50]. In the operating room, glucose is removed from the intravenous solution to allow glucose monitoring with a rise in glucose anticipated within minutes to an hour after insulinoma resection [50]. Small doses of insulin may be required during the first postoperative days. After surgery for large insulinomas, patients may need glucose infusion as insulin effects may still prevail for some time, and blood glucose levels should be monitored. Preoperative octreotide infusion should only be considered after the effect of this therapy is electively studied. In some insulinoma patients, octreotide infusion might lead to more severe hypoglycemias by suppression of the contraregulatory hormones. It is claimed that only in half of the nonmetastatic or benign insulinomas might octreotide have a positive effect [51].

\section{Glucagonoma}

Glucagonoma patients may have troublesome skin disease and some patients may be cachectic. Somatostatin analog treatment, amino acid infusion, and antibiotics may improve the condition and heal the skin lesion before surgery [52]. Patients have substantial risk for deep vein thrombosis and pulmonary embolism, and should perioperatively receive prophylactic high-dose molecular heparin as anticoagulation treatment [53].

\section{VIPoma}

In VIPoma patients, secretory diarrhea is generally extensive, with severe loss of potassium and bicarbonate leading to metabolic acidosis, dehydration, and hypokalemia [52]. Patients need to be resuscitated from lifethreatening fluid losses and electrolyte abnormalities with somatostatin analog treatment, as well as intravenous and electrolyte therapy, before being subjected to surgery.

\section{Syndromes Related to Ectopic Hormonal Secretion}

Occasionally the substances secreted by gastrointestinal NET are not directly related to the tissue of origin and the corresponding clinical syndromes are related to these ectopically secreted compounds [54]. Appreciation of the presence of such syndromes is highly relevant, because if the clinical presentation is not identified, it may delay the diagnosis of the underlying neoplasia and lead to increased morbidity and mortality. Some of these syn- 
dromes, such as Cushing syndrome due to ectopic adrenocorticotrophic hormone and hypercalcemia due to ectopic parathyroid hormone-related peptide secretion, may markedly increase the operative risk and need to be adequately treated prior to any intervention [54]. In patients with uncontrolled hormonal syndrome due to ectopic hormone secretion, hepatic artery embolization or chemoembolization and/or debulking surgery can be discussed.

Adrenocorticotrophic hormone secretion leading to Cushing syndrome has mostly been encountered with lung NET, but can occasionally be seen with gastrointestinal tumors $[54,55]$. Drugs aiming at controlling the hormonal secretion, either at the tumor level (somatostatin analogs, cabergoline), the adrenals (metyrapone, ketoconazole, $\mathrm{O}, \mathrm{p}^{\prime}$-DDD) or rarely the glucocorticoid receptor, markedly reduce the operative risk, which may be considerably high if the hypercortisolism remains untreated [56]. In refractory cases, intravenous etomidate has successfully been used but requires intensive monitoring [57]. Hypersecretion of parathyroid hormone-related peptide by metastatic NET seems to be exclusively associated with metastatic pancreatic NET and has a major clinical impact because poorly controllable hypercalcemia is associated with increased morbidity and mortality [58]. In such cases and other more rare syndromes, early diagnosis and management are essential [54].

\section{Minimal Consensus Statement on Preoperative Evaluation and Therapy}

Preoperatively, patients with NET and carcinoid syndrome need to be carefully evaluated. Patients with severe diarrhea, weight loss, vitamin deficiencies, and hypoproteinemia require parenteral nutrition and adequate supplementation for reversal of fluid, electrolyte, vitamin and protein abnormalities, before major surgery is undertaken. Patients with carcinoid syndrome should be examined with echocardiography and NT-proBNP measurement to diagnose the possible presence of incipient $\mathrm{CHD}$ prior to abdominal surgery. Even patients with moderate CHD should be discussed with cardiologists before surgery as symptoms may be absent in a significant number of patients. In case of significant heart disease, a thoracic surgical evaluation and possible surgical revision of valvular heart disease should be considered before major abdominal operation, especially liver resection, is undertaken.

Pre- and Perioperative Therapy in

Patients with Neuroendocrine Tumours

\section{Minimal Consensus Statement on Perioperative Prophylaxis and Treatment to Prevent Carcinoid Crisis}

Patients with carcinoid syndrome should receive octreotide prophylaxis to prevent the development of carcinoid crisis during surgery. Patients with $\mathrm{CHD}$ and/or high 5-HIAA levels are at higher risk. If patients already receive octreotide or other somatostatin analogs, this medication should be continued while awaiting surgery. Patients who have not received octreotide can be given 100-200 $\mu \mathrm{g} 3$ times/day subcutaneously for 2 weeks prior to surgery. If more acute operation is needed, octreotide is given as an intravenous infusion for 1-2 days before surgery. Perioperative treatment is recommended with intravenous octreotide; infusion is started $12 \mathrm{~h}$ before anesthesia at a dose of $50-100 \mu \mathrm{g} / \mathrm{h}$ using dose titration until resolution of the symptoms (mean dose 100-200 $\mu \mathrm{g} / \mathrm{h}$ ). Remaining symptoms of carcinoid syndrome indicate the need for additional intravenous octreotide. In case of a carcinoid crisis reaction with hypotension during anesthesia, adrenergic drugs should be used cautiously and further octreotide infusion should be given even at doses as high as $500 \mu \mathrm{g} / \mathrm{h}$. Patients previously treated with somatostatin analogs may require even higher doses.

\section{Minimal Consensus Statement on Recommendation Concerning Anesthesia}

Monitoring of central venous pressure is of value during surgery for NET with carcinoid syndrome, but may be difficult to interpret in the presence of CHD with rightsided failure. Preoperative medication and anesthesia should exclude drugs that may stimulate the sympathetic system or cause histamine release. If hypotension occurs, sympathomimetic drugs should be used cautiously, and increased intravenous octreotide should be given. Hypotension is treated by the prevention of peptide release with octreotide, and by increasing the depth of anesthesia. In the presence of bronchospasm, $\beta$-receptor agonists should be used with great care or, instead, octreotide is recommended, possibly together with steroids (dexamethasone). Flushing during anesthesia should constitute a warning of cardiovascular instability and indicates increased requirement of octreotide. Preoperative treatment with octreotide should continue and be weaned slowly over the first postoperative week rather than abruptly stopped. Hypovolemia and pain-causing sympathetic stimulation should be avoided in the postopera-

Neuroendocrinology 2017;105:245-254

DOI: $10.1159 / 000461583$
251 
tive period. Non-histamine-releasing opioids such as fentanyl have been used with no adverse effects for postoperative analgesia.

\section{Minimal Consensus Statement on Pre- and Perioperative Management of Pancreaticoduodenal NET}

Patients with gastrinoma require treatment with a titrated dose of PPIs before, during and few weeks after the operation to be protected from hypersecretion. Insulinoma patients should be subjected to careful glucose monitoring during and after surgery. Patients with glucagonoma require somatostatin analog treatment and nutritional supplementation to heal the skin lesion prior to surgery, and perioperative anticoagulation to prevent thrombosis. Patients with VIPoma need to be resuscitated with preoperative somatostatin analog treatment and intravenous fluid and electrolyte therapy before being subjected to surgery. A high index of suspicion is required to identify syndromes related to ectopic hormonal secretion prior to surgery and initiate appropriate treatment.

\section{Appendix}

Other Antibes Consensus Conference Participants

Arnold, R. (Munich, Germany); Bartsch, D.K. (Department of Surgery, Philipps University, Marburg, Germany); Baudin, E. (Département de Médecine, Gustave Roussy Cancer Campus, Paris South University, Villejuif, France); Borbath, I. (Service de Gastroenterologie, Cliniques Universitaires St-Luc, Bruxelles, Belgium); Capdevila, J. (Vall d'Hebron University Hospital, Teknon Institute of Oncology, Barcelona, Spain); Chen, Y.-J. (Peking Union Medical College Hospital, Chinese Academy of Medical Sciences, Beijing, China); Costa, F. (Hospital Sírio Libanês, São Paulo, Brazil); Couvelard, A. (Service de Pathologie, Hôpital Bichat, Paris, France); Cwikla, J.B. (Department of Radiology, Faculty of Medical Sciences, University of Warmia and Mazury, Olsztyn, Poland); Delle Fave, G. (Department of Digestive and Liver Disease, Ospedale Sant'Andrea, Rome, Italy); Eriksson, B. (Department of Endocrine Oncology, Uppsala University Hospital, Uppsala, Sweden); Falkerby, J. (Deptartment of Endocrine Oncology, Uppsala University Hospital, Uppsala, Sweden); Fazio, N. (Unit of Gastrointestinal Medical Oncology and Neuroendocrine Tumors, European Institute of Oncology, Milan, Italy); Gorbunova, V. (Department of Oncology, Institution of Russian Academy of Medical Sciences); Gross, D. (Department of Endocrinology and Metabolism, Hadassah University Hospital, Mevasseret Zion, Israel); Grossman, A. (Oxford Centre for Diabetes, Endocrinology and Metabolism, Churchill Hospital, Oxford, UK); Hicks R.J. (Cancer Imaging, the Peter MacCallum Cancer Centre, Melbourne, VIC, Australia); Jensen, R.T. (Digestive Diseases Branch, NIH, Bethesda, MD, USA); Kaltsas, G. (Department of Pathophysiology, Division of Endocrinology, National University of Athens, Athens, Greece); Knigge, U. (Neuroendocrine Tumor Center of Excellence, Rigshospital, Copenhagen University Hospital, Copenhagen, Denmark); Krenning, E.P. (Cyclotron Rotterdam BV, Erasmus MC, Rotterdam, The Netherlands); Kulke, M.H. (Dana-Farber Cancer Institute, Harvard Medical School, Boston, MA, USA); Kwekkeboom, D.J. (Department of Internal Medicine, Division of Nuclear Medicine, ENETS Centre of Excellence Rotterdam, Erasmus MC, Rotterdam, The Netherlands); Lombard-Bohas, C. (Medical Oncology Department, Hôpital Edouard Herriot, Hospices Civils de Lyon, Lyon, France); Niederle, B. (Department of Surgery, Medical University of Vienna, Vienna, Austria); Nieveen van Dijkum, E.J.M. (Department of Surgery, Academic Medical Center, Amsterdam, The Netherlands); Öberg, K. (Department of Medical Sciences, Endocrine Oncology Unit, University Hospital, Uppsala, Sweden); O’Connor, J. (Department of Clinical Oncology, Institute Alexander Fleming, Buenos Aires, Argentina); O’Toole, D. (NET Centre, St. Vincent's University and Department of Clinical Medicine, St James Hospital and Trinity College, Dublin, Ireland); Pape, U.-F. (Department of Hepatology and Gastroenterology, Campus Virchow Klinikum, Charité Universitätsmedizin Berlin, Berlin, Germany); Pascher, A. (Department of Surgery, Charité Universitätsmedizin Berlin, Berlin, Germany); Perren A. (Institute of Pathology, University of Bern, Switzerland); Ramage, J. (Gastroenterology Department, Hampshire Hospitals NHS Trust, Hampshire, UK); Reed, N. (Beatson Oncology Centre, Gartnavel General Hospital, Glasgow, UK); Rindi, G. (Institute of Anatomic Pathology, Policlinico A. Gemelli, Università Cattolica del Sacro Cuore, Rome, Italy); Ruszniewski, P. (Department of Gastroenterology, Beaujon Hospital, Clichy, France); Scoazec, J.-Y. (Services de Pathologie Morphologique et Moléculaire, Département de Biologie et Pathologie Médicales, Gustave Roussy Cancer Campus, Villejuif, France); Sorbye, H. (Department of Oncology, Haukeland University Hospital, Bergen, Norway); Sundin, A. (Department of Radiology, Institute Surgical Sciences, Uppsala University, Uppsala University Hospital, Uppsala, Sweden); Toumpanakis, C. (Neuroendocrine Tumour Unit, Royal Free Hospital, London, UK); Valle, J.W. (Department of Medical Oncology, The Christie NHS Foundation Trust, University of Manchester/Institute of Cancer Sciences, Manchester, UK); Vullierme M.-P. (Service de Gastroentérologie, Hôpital Beaujon, Clichy, France); Welin, S. (Department of Medical Sciences, Endocrine Oncology, Uppsala University, Sweden); Wiedenmann, B. (Department of Hepatology and Gastroenterology, Campus Virchow Klinikum, Charité Universitätsmedizin Berlin, Berlin, Germany).

References

1 Modlin IM, Oberg K, Chung DC, Jensen RT, de Herder WW, Thakker RV, Caplin M, Delle Fave G, Kaltsas GA, Krenning EP, Moss SF, Nilsson O, Rindi G, Salazar R, Ruszniewski P, Sundin A: Gastroenteropancreatic neuroendocrine tumours. Lancet Oncol 2008;9:6172.

2 Mancuso K, Kaye AD, Boudreaux JP, Fox CJ, Lang P, Kalarickal PL, Gomez S, Primeaux PJ: Carcinoid syndrome and perioperative anesthetic considerations. J Clin Anesth 2011;23: 329-341.
Kaltsas et al. 
3 Bhattacharyya S, Raja SG, Toumpanakis C, Caplin ME, Dreyfus GD, Davar J: Outcomes, risks and complications of cardiac surgery for carcinoid heart disease. Eur J Cardiothorac Surg 2011;40:168-172.

4 Soga J: Carcinoids and their variant endocrinomas. An analysis of 11,842 reported cases. J Exp Clin Cancer Res 2003;22:517-530.

5 Ansell JK, Stebbings WS: Carcinoid syndrome due to a primary ovarian carcinoid tumour. J R Soc Med 1993;86:668.

6 Tomassetti P, Migliori M, Lalli S, Campana D, Tomassetti V, Corinaldesi R: Epidemiology, clinical features and diagnosis of gastroenteropancreatic endocrine tumours. Ann Oncol 2001;12(suppl 2):S95-S99.

7 Vaughan DJ, Brunner MD: Anesthesia for patients with carcinoid syndrome. Int Anesthesiol Clin 1997;35:129-142.

8 Graham GW, Unger BP, Coursin DB: Perioperative management of selected endocrine disorders. Int Anesthesiol Clin 2000;38:3167.

9 Bouma G, Van FM, Kats-Ugurlu G, de Vries EG, Kema IP, Walenkamp AM: Niacin (vitamin $B_{3}$ ) supplementation in serotonin producing neuroendocrine tumor patients. Neuroendocrinology 2016;103:489-494.

10 Fiebrich HB, van den Berg G, Kema IP, Links TP, Kleibeuker JH, van Beek AP, Walenkamp AM, Sluiter WJ, de Vries EG: Deficiencies in fat-soluble vitamins in long-term users of somatostatin analogue. Aliment Pharmacol Ther 2010;32:1398-1404.

11 Connolly HM, Schaff HV, Mullany CJ, Rubin J, Abel MD, Pellikka PA: Surgical management of left-sided carcinoid heart disease. Circulation 2001;104:I36-I40.

12 Pellikka PA, Tajik AJ, Khandheria BK, Seward JB, Callahan JA, Pitot HC, Kvols LK: Carcinoid heart disease. Clinical and echocardiographic spectrum in 74 patients. Circulation 1993;87:1188-1196.

13 Grozinsky-Glasberg S, Grossman AB, Gross DJ: Carcinoid heart disease: from pathophysiology to treatment - "something in the way it moves." Neuroendocrinology 2015; 101:263273.

14 Bhattacharyya S, Toumpanakis C, Caplin ME, Davar J: Analysis of 150 patients with carcinoid syndrome seen in a single year at one institution in the first decade of the twentyfirst century. Am J Cardiol 2008; 101:378-381.

15 Adaway JE, Dobson R, Walsh J, Cuthbertson DJ, Monaghan PJ, Trainer PJ, Valle JW, Keevil BG: Serum and plasma 5-hydroxyindoleacetic acid as an alternative to 24 -h urine 5-hydroxyindoleacetic acid measurement. Ann Clin Biochem 2016;53:554-560.

16 Korse CM, Taal BG, de Groot CA, Bakker RH, Bonfrer JM: Chromogranin-A and N-terminal pro-brain natriuretic peptide: an excellent pair of biomarkers for diagnostics in patients with neuroendocrine tumor. J Clin Oncol 2009;27:4293-4299.
17 Castillo JG, Filsoufi F, Adams DH, Raikhelkar J, Zaku B, Fischer GW: Management of patients undergoing multivalvular surgery for carcinoid heart disease: the role of the anaesthetist. Br J Anaesth 2008;101:618-626.

18 Sarmiento JM, Que FG: Hepatic surgery for metastases from neuroendocrine tumors. Surg Oncol Clin N Am 2003;12:231-242.

19 Lundin L, Hansson HE, Landelius J, Oberg K: Surgical treatment of carcinoid heart disease. J Thorac Cardiovasc Surg 1990;100:552-561.

20 Botero M, Fuchs R, Paulus DA, Lind DS: Carcinoid heart disease: a case report and literature review. J Clin Anesth 2002;14:57-63.

21 Manoly I, McAnelly SL, Sriskandarajah S, McLaughlin KE: Prognosis of patients with carcinoid heart disease after valvular surgery. Interact Cardiovasc Thorac Surg 2014;19: 302-305.

22 Ahlman $\mathrm{H}$, Wangberg B, Nilsson O, Grimelius L, Granerus G, Modlin IM, Stenqvist O, Schersten T: Aspects on diagnosis and treatment of the foregut carcinoid syndrome. Scand J Gastroenterol 1992;27:459-471.

23 Westberg G, Wangberg B, Ahlman H, Bergh $\mathrm{CH}$, Beckman-Suurkula M, Caidahl K: Prediction of prognosis by echocardiography in patients with midgut carcinoid syndrome. $\mathrm{Br}$ J Surg 2001;88:865-872.

24 Janssen M, Salm EF, Breburda CS, van Woerkens LJ, de Herder WW, Zwaan C, Roelandt JR: Carcinoid crisis during transesophageal echocardiography. Intensive Care Med 2000;26:254.

25 de Keizer B, van Aken MO, Feelders RA, de Herder WW, Kam BL, van Essen M, Krenning EP, Kwekkeboom DJ: Hormonal crises following receptor radionuclide therapy with the radiolabeled somatostatin analogue [177Lu-DOTA0, Tyr3] octreotate. Eur J Nucl Med Mol Imaging 2008;35:749-755.

26 Kinney MA, Warner ME, Nagorney DM, Rubin J, Schroeder DR, Maxson PM, Warner MA: Perianaesthetic risks and outcomes of abdominal surgery for metastatic carcinoid tumours. Br J Anaesth 2001;87:447-452.

27 Massimino K, Harrskog O, Pommier S, Pommier R: Octreotide LAR and bolus octreotide are insufficient for preventing intraoperative complications in carcinoid patients. J Surg Oncol 2013;107:842-846.

28 Warner RR, Mani S, Profeta J, Grunstein E: Octreotide treatment of carcinoid hypertensive crisis. Mt Sinai J Med 1994;61:349-355.

29 Balestrero LM, Beaver CR, Rigas JR: Hypertensive crisis following meperidine administration and chemoembolization of a carcinoid tumor. Arch Intern Med 2000;160:23942395.

30 Jones RM, Knight D: Severe hypertension and flushing in a patient with a non-metastatic carcinoid tumour. Hypertension and flushing with a solitary carcinoid tumour. Anaesthesia 1982;37:57-59.
31 Seymour N, Sawh SC: Mega-dose intravenous octreotide for the treatment of carcinoid crisis: a systematic review. Can J Anaesth 2013; 60:492-499.

32 Kiesewetter B, Raderer M: Ondansetron for diarrhea associated with neuroendocrine tumors. N Engl J Med 2013;368:1947-1948.

33 Dierdorf SF: Carcinoid tumor and carcinoid syndrome. Curr Opin Anaesthesiol 2003; 16 : 343-347.

34 Ahlman H, Ahlund L, Dahlstrom A, Martner J, Stenqvist O, Tylen U: SMS 201-995 and provocation tests in preparation of patients with carcinoids for surgery or hepatic arterial embolization. Anesth Analg 1988;67:11421148.

35 Papadogias D, Makras P, Kossivakis K, Kontogeorgos G, Piaditis G, Kaltsas G: Carcinoid syndrome and carcinoid crisis secondary to a metastatic carcinoid tumour of the lung: a therapeutic challenge. Eur J Gastroenterol Hepatol 2007;19:1154-1159.

36 Kolby L, Nilsson O, Ahlman H: Gastroduodenal endocrine tumours. Scand J Surg 2004;93: 317-323.

37 Farling PA, Durairaju AK: Remifentanil and anaesthesia for carcinoid syndrome. Br J Anaesth 2004;92:893-895.

38 Soreide O, Berstad T, Bakka A, Schrumpf E, Hanssen LE, Engh V, Bergan A, Flatmark A: Surgical treatment as a principle in patients with advanced abdominal carcinoid tumors. Surgery 1992;111:48-54.

39 Harris CE, Murray AM, Anderson JM, Grounds RM, Morgan M: Effects of thiopentone, etomidate and propofol on the haemodynamic response to tracheal intubation. Anaesthesia 1988;43(suppl):32-36.

40 Mason RA, Steane PA: Carcinoid syndrome: its relevance to the anaesthetist. Anaesthesia 1976;31:228-242.

41 Nishimura RA, Carabello BA, Faxon DP, Freed MD, Lytle BW, O'Gara PT, O'Rourke RA, Shah PM, Bonow RO, Carabello BA, Chatterjee K, de Leon ACJ, Faxon DP, Freed MD, Gaasch WH, Lytle BW, Nishimura RA, O'Gara PT, O'Rourke RA, Otto CM, Shah PM, Shanewise JS, Smith SC, Jr., Jacobs AK, Buller CE, Creager MA, Ettinger SM, Krumholz HM, Kushner FG, Lytle BW, Nishimura RA, Page RL, Tarkington LG, Yancy CW Jr: ACC/AHA 2008 guideline update on valvular heart disease: focused update on infective endocarditis: a report of the American College of Cardiology/American Heart Association Task Force on Practice Guidelines: endorsed by the Society of Cardiovascular Anesthesiologists, Society for Cardiovascular Angiography and Interventions, and Society of Thoracic Surgeons. Circulation 2008;118:887896.

42 Monteith K, Roaseg OP: Epidural anaesthesia for transurethral resection of the prostate in a patient with carcinoid syndrome. Can J Anaesth 1990;37:349-352.
Pre- and Perioperative Therapy in

Patients with Neuroendocrine Tumours
Neuroendocrinology 2017;105:245-254

DOI: $10.1159 / 000461583$ 
43 Alghamdi AA, Jawas AM, Hart RS: Use of octreotide for the prevention of pancreatic fistula after elective pancreatic surgery: a systematic review and meta-analysis. Can J Surg 2007;50:459-466.

44 Kurumboor P, Palaniswami KN, Pramil K, George D, Ponnambathayil S, Varma D, Aikot S: Octreotide does not prevent pancreatic fistula following pancreatoduodenectomy in patients with soft pancreas and non-dilated duct: a prospective randomized controlled trial. J Gastrointest Surg 2015;19:2038-2044.

45 Yeo CJ, Cameron JL, Lillemoe KD, Sauter PK, Coleman J, Sohn TA, Campbell KA, Choti MA: Does prophylactic octreotide decrease the rates of pancreatic fistula and other complications after pancreaticoduodenectomy? Results of a prospective randomized placebocontrolled trial. Ann Surg 2000;232:419-429.

46 Cisco RM, Norton JA: Surgery for gastrinoma. Adv Surg 2007;41:165-176.

47 Lew EA, Pisegna JR, Starr JA, Soffer EF, Forsmark C, Modlin IM, Walsh JH, Beg M, Bochenek W, Metz DC: Intravenous pantoprazole rapidly controls gastric acid hypersecretion in patients with Zollinger-Ellison syndrome. Gastroenterology 2000;118:696-704.
48 Ruszniewski P, Ramdani A, Cadiot G, Lehy T, Mignon M, Bonfils S: Long-term treatment with octreotide in patients with the ZollingerEllison syndrome. Eur J Clin Invest 1993;23: 296-301.

49 Ito $\mathrm{T}$, Igarashi $\mathrm{H}$, Uehara H, Jensen RT: Pharmacotherapy of Zollinger-Ellison syndrome. Expert Opin Pharmacother 2013;14:307-321.

50 Grant CS: Insulinoma. Best Pract Res Clin Gastroenterol 2005;19:783-798.

51 de Herder WW, van Schaik E, Kwekkeboom D, Feelders RA: New therapeutic options for metastatic malignant insulinomas. Clin Endocrinol (Oxf) 2011;75:277-284.

52 Doherty GM: Rare endocrine tumours of the GI tract. Best Pract Res Clin Gastroenterol 2005;19:807-817.

53 Kindmark H, Sundin A, Granberg D, Dunder K, Skogseid B, Janson ET, Welin S, Oberg K, Eriksson B: Endocrine pancreatic tumors with glucagon hypersecretion: a retrospective study of 23 cases during 20 years. Med Oncol 2007;24:330-337.

54 Kaltsas G, Androulakis II, de Herder WW, Grossman AB: Paraneoplastic syndromes secondary to neuroendocrine tumours. Endocr Relat Cancer 2010;17:R173-R193.
55 Maragliano R, Vanoli A, Albarello L, Milione M, Basturk O, Klimstra DS, Wachtel A, Uccella S, Vicari E, Milesi M, Davi MV, Scarpa A, Sessa F, Capella C, La Rosa S: ACTH-secreting pancreatic neoplasms associated with Cushing syndrome: clinicopathologic study of 11 cases and review of the literature. Am J Surg Pathol 2015;39:374-382.

56 van der Pas R, de Herder WW, Hofland LJ, Feelders RA: New developments in the medical treatment of Cushing's syndrome. Endocr Relat Cancer 2012;19:R205-R223.

57 Preda VA, Sen J, Karavitaki N, Grossman AB: Etomidate in the management of hypercortisolaemia in Cushing's syndrome: a review. Eur J Endocrinol 2012;167:137-143.

58 Kamp K, Feelders RA, van Adrichem RC, de Rijke YB, van Nederveen FH, Kwekkeboom DJ, de Herder WW: Parathyroid hormonerelated peptide (PTHrP) secretion by gastroenteropancreatic neuroendocrine tumors (GEP-NETs): clinical features, diagnosis, management, and follow-up. J Clin Endocrinol Metab 2014;99:3060-3069. 